\title{
O GÊNERO DA CIÊNCIA. REFLEXÕES SOBRE A TEORIA ATOR-REDE E A PERSPECTIVA FEMINISTA
}

\author{
Gabriel Pugliese ${ }^{1}$
}

\begin{abstract}
RESUMO
0 presente artigo problematiza alguns dos princípios que orientam as formas descritivas da Teoria Ator-Rede (ANT), de Bruno Latour, e da teoria feminista, sobre 0 "ponto de vista" formulada por Sandra Harding e Evelyn Fox Keller, por meio de minha pesquisa sobre o "Caso Marie Curie". Como um caso singular entre gênero e ciência, o objetivo desse artigo é jogar as certezas da ANT contra as incertezas da perspectiva feminista, e as certezas da perspectiva feminista contra as incertezas da ANT. Isto é, reagir - no sentido químico do verbo - às formas descritivas da Teoria Ator-Rede e da perspectiva feminista "desobviando" alguns de seus pressupostos. Trata-se de explorar as decorrências dessas reações e seus efeitos para a descrição que fazemos da ciência.
\end{abstract}

Palavras-chave: Teoria Ator-Rede. Teoria feminista. Ciência. Gênero. Antropologia

\section{THE GENDER OF SCIENCE: REFLECTIONS ON THE ACTOR- NETWORK THEORY AND THE FEMINIST PERSPECTIVE}

\begin{abstract}
This article discusses some of the principles that guide the descriptive forms of the actor-network theory (ANT) of Bruno Latour and feminist standpoint theory formulated by Sandra Harding and Evelyn Fox Keller, through my research on the "Marie Curie Case". As a singular case between gender and science, the goal of this

\footnotetext{
${ }^{1}$ Professor de Antropologia no Curso de Ciências Sociais da Universidade Federal do Vale do São Francisco (UNIVASF), Brasil. gabopugliese@gmail.com
} 
paper is to play with ANT certainties against feminist perspective uncertainties. In the other hand, the certainties of feminist perspective are put against the uncertainties of ANT. With this counterpoint we intend to promote a reaction - in the chemical sense of the word - to the descriptive forms of the actor-network theory and feminist perspective taking away the obviousness of some of their assumptions. Doing that, we explore the moves of those reactions and their effects to the description which we do about science.

Keywords: Actor-network theory. Feminist theory. Science. Gender. Anthropology

\section{O JOGO}

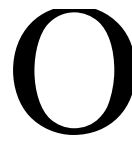

horizonte deste artigo é explorar e problematizar alguns dos princípios que orientam as formas descritivas da Teoria Ator-Rede (ANT) de Bruno Latour $(2002 ; 2012)$ e da teoria feminista sobre o "ponto de vista" formulada por Sandra Harding (1986) e Evelyn Fox Keller (1985). Esse tema, que tentei levantar em um outro momento da pesquisa de forma prematura (PUGLIESE, 2012a), pretendo retomar aqui com mais espaço e maior discernimento diante da distância estabelecida com minha pesquisa.

Ao tratar a ANT e perspectiva feminista - que têm partidas e interesses diferentes - uma a partir do ângulo da outra, pretendo abrir fissuras teóricas que possam criar questões tanto para os estudos feministas como para os estudos da ciência. Inspirando-me em Marilyn Strathern (1999; 2006), o objetivo geral desse artigo é jogar as certezas da ANT contra as incertezas da perspectiva feminista, e as certezas da perspectiva feminista contra as incertezas da ANT. Será preciso para tanto, fazer um esforço de tratar seus mecanismos como dois instrumentos que reagem a determinados problemas de maneira distinta. Isto posto, a ideia é explorar as decorrências dessas reações e seus efeitos para a descrição que fazemos da ciência.

Não é difícil, todavia, encontrar paralelos em relação a algumas questões que orientam a ANT e a perspectiva feminista. De modo que, muitas vezes, essas ferramentas são mobilizadas em conjunto quando se trata de estudar gênero e ciência. Ambas teorias são respostas à filosofia da ciência tradicional: combatem a noção transcendente de objetividade científica, um certo sentimento de modernidade que contém um pernicioso jogo entre 0 absoluto e o relativo, colocam a questão da agência das coisas (de maneira bastante diferente, é verdade), entre outros elementos. Do ponto de vista geral esses paralelos são 
evidentes, não somente pela influência mútua exercida. Assim, minha questão é menos pensar uma tentativa aglutinadora de questões e respostas entre a ANT e a perspectiva feminista e mais o jogo de certezas e incertezas que cada campo teórico carrega em seu território quando colocado frente a problemas específicos. Por esse motivo, esse movimento não pode ser feito somente de um ponto de vista abstrato, ou metateórico. Afinal, o rendimento dessas ferramentas está vinculado a suas capacidades empírico-descritivas de acontecimentos, e seus alcances jamais estão descolados de domínios bem específicos entre os assuntos humanos e 0 plano das coisas. Por esse motivo, esse artigo não é simplesmente uma revisão teórica ou mesmo um ensaio explanatório desses dois conjuntos teóricos.

0 jogo que pretendo criar, evidentemente, diz respeito tanto a problemas com mulheres na ciência como em relação ao próprio gênero da ciência, isto é, de sua singularidade em comparação com outras formas de conhecimento do mundo. Dessa perspectiva, o meio pelo qual coloco os problemas em jogo é meu estudo sobre o "Caso Marie Curie" (PUGLIESE, 2012a). Em alguma medida, toda a questão nessa pesquisa era emulsionar a ANT e as teorias feministas da ciência para uma descrição das relações de gênero em sua conexão com a invençãodescoberta da radioatividade. 0 problema foi que 0 emulsionante nunca funcionou, seja por incapacidade de minha parte, ou mesmo por teimosia, fui levado a passar de um registro teórico a outro toda vez que essas ferramentas esbarravam na singularidade do "Caso Marie Curie". 0 fato é que em alguns pontos fundamentais a perspectiva feminista e a ANT divergem.

0 "Caso Marie Curie" é um bom exemplo das dificuldades que as mulheres enfrentam na ciência - esse território historicamente masculino - e a história de Marie Curie, nesse sentido, é marcada por essas relações de poder. Por outro lado, pelo fato de Marie Curie ter sido uma cientista extremamente vitoriosa, tendo seu nome ligado ao fenômeno universal da radioatividade, seu "caso" também se tornou um bom exemplo para se descrever o gênero da ciência: como a atividade científica desloca outras relações tornando-as secundárias.

Marie Curie integra a pequena lista de cientistas que conquistou o prêmio Nobel, uma das condecorações hoje consideradas das mais louváveis na comunidade científica, e ainda com a façanha de tê-lo recebido por duas vezes: 0 primeiro por conta das pesquisas sobre radioatividade e o segundo pela purificação do elemento químico rádio. Além disso, é a única que recebeu 0 prêmio em categorias diferentes: o primeiro em Física, em 1903, dividido com Pierre Curie (seu esposo) e com Henri Becquerel; e o segundo, sozinha, em 
Química, no ano de 1911. Em mais de cem anos do Nobel, somente duas mulheres ganharam em física, e três em química ${ }^{2}$.

Fatos duros são raros, disse Latour (2001), e a radioatividade certamente é um desses acontecimentos. Mulheres com visibilidade nas Hard Sciences são tão raras quanto os fatos duros - ainda nos dias de hoje (KELLER \& LONGINO, 1996), sendo que Marie Curie representa uma exceção na história das ciências.

\section{O GÊNERO ENTRE ASSOCIAÇÕES DE HUMANOS E NÃO HUMANOS}

Talvez o princípio mais importante da ANT seja 0 acompanhamento abstrato-descritivo de associações de qualquer forma, tendo como ponto de partida as controvérsias. Bruno Latour insiste que não descreve redes propriamente ditas, mas problematiza as diversas formas da realidade a partir do ator-rede, isto é, os movimentos dos atores no mundo, seu alistamento em determinados agrupamentos, assim como o desmantelamento dos mesmos. A ANT evita assim, fazer o analista "saltar de plano", criando explicações transcendentes ao próprio objeto de descrição. Enquanto uma ontologia plana, ela permite acompanhar simetricamente os rastros dos atores (ou actantes) humanos e não-humanos em meio às diversas relações que os sustentam.

Desse modo, como método descritivo, a ANT tem como característica a necessidade trabalhosa de não explicar nada de antemão, mas permitir que uma boa descrição seja a própria explicação dos acontecimentos. A explicação dos acontecimentos sempre estará do lado das associações entre humanos e não humanos. "Social é o nome de um tipo de associação momentânea caracterizada pelo modo como se aglutina assumindo novas formas" (LATOUR, 2012, p. 100). Os coletivos são desse modo um conjunto de associações entre actantes heterogêneos, conectados uns aos outros por relações móveis. De meu ponto de vista, descrever as práticas científicas do "casal Curie" nesses termos tem seus limites.

Se 0 doutoramento de Marie Curie for o ponto de partida, todo 0 amálgama de relações estabelecidas, de instrumentos de medição recrutados, minérios convidados a participar, e de novas entidades desenhadas como fenômenos, têm seu lastro no auxílio de Pierre Curie. De algum modo, Pierre Curie foi um primeiro aliado importante daquilo que veio a ser a radioatividade, visto que ao se

\footnotetext{
${ }^{2}$ Em física: Marie Curie (1903) dividido e Maria Goeppert Maver (1963), também dividido. Em Química: Marie Curie (1911) sozinha, Irene Joliot-Curie (1935) divido e Dorothy Hodgkin (1964) também sozinha. Cf. www.nobelprize.org.
} 
posicionar "junto com" as pesquisas da esposa, permitiu a conquista dos recursos mínimos e necessários a sua pesquisa. Além disso, a primeira publicação dos resultados por parte de Marie Curie, representada por seu antigo professor ${ }^{3}$, surpreendentemente - isso é uma ironia - não teve nenhuma repercussão, mesmo quando a cientista havia sugerido claramente a existência de um novo elemento químico e de um fenômeno atômico geral, o que não acontecia todos os dias. Somente quando Pierre deixou de lado suas pesquisas pessoais para "ajudar" a esposa na grande empreitada que ela havia inaugurado, assinando em conjunto as comunicações científicas, os resultados passaram a ser debatidos ${ }^{4}$.

Não por outros motivos, os cientistas se mobilizavam para estudar esse fenômeno estudado pelo "casal". Esses motivos são, evidentemente, os fenômenos que Marie Curie fez aparecer, que se não foram suficientes para interessar a comunidade científica, serviram para interessar Pierre Curie, que quando passou a assinar as comunicações em conjunto, carregou o interesse da comunidade científica abrindo toda uma controvérsia sobre a radioatividade, orientada pelo novo estatuto da política sexual dado a configuração do "casal". E quando se trata de ciência, "a simples abertura de uma controvérsia experimental já é um sucesso: um enunciado conseguiu interessar os colegas tidos como preparados para pô-lo à prova. Interessar-se é a condição prévia necessária a toda controvérsia, todo teste" (STENGERS, 2002, p. 112).

Assim, a participação de Pierre Curie na formação do casal pesquisador produziu uma transformação que permitia Marie Curie habitar 0 interior da comunidade científica, porém, lançada para um lugar estranho; sua borda, o lado de dentro da margem, de forma a conjurar sua diferença. Já se tornava indistinguível se Pierre capturara a radioatividade em seu nome ou se a própria radioatividade capturara 0 cientista em seu aparelho de reprodução. Pois, ao levar a empreitada da radioatividade adiante, Pierre Curie não fazia outra coisa senão

\footnotetext{
${ }^{3}$ Segundo as regras da Academia de Ciências francesa, mulheres e não membros não poderiam apresentar seus trabalhos, por isso nem mesmo Pierre pôde "fazer as honras", ficando ao encargo de Gabriel Lippman, então professor de Marie Curie.

${ }^{4}$ Esse trabalho conjunto durou até a morte de Pierre Curie, em 1906. Seu falecimento precoce alterou (mais uma vez) o funcionamento da política sexual, já que Marie Curie ficou isolada da batuta do casal. No entanto, como nesse momento a radioatividade representava todo um campo de pesquisa e Marie Curie era portadora dos preciosos sais de rádio, mas também de prestígio na área, suas participações nas pesquisas eram garantidas pela borda, na qualidade de exceção, e na maioria das vezes por meio do trabalho químico. Esse acontecimento é descrito com mais precisão em um outro artigo (PUGLIESE, 2012b).
} 
abrir a possibilidade para Marie Curie "ir junto com o casal", alimentada pela própria política estabelecida através da criação da controvérsia da radioatividade.

Marie Curie estava habitando, como cientista, um dos centros das Hard Sciences da virada do século, e isso sem dúvida está vinculado ao "auxílio" de seu marido a sua pesquisa, 0 aliado que permitiu produzir toda uma rede de aliados. Se Marie não produzisse um dispositivo experimental que "salvasse o fenômeno desconhecido" e convencesse Pierre Curie daquilo que estava experimentando, e se ele movido pelas pesquisas de sua esposa não se colocasse a trabalhar em nome daquilo que viria a ser a radioatividade, colocando em jogo um novo estatuto de gênero à disposição das relações, a radioatividade não seria 0 fenômeno que conhecemos. Afinal como bem colocou Alfred North Whitehead: "Se desejamos obter um registro de uma experiência não interpretada, é melhor pedir a uma pedra para registrar a sua própria autobiografia" (apud STENGERS, 2000, p. 326).

Mas aqui se estabelece um primeiro problema que aponta para os limites da ANT. As "associações" entre homens, mulheres e as coisas também têm importantes liames a serem explorados. Refiro-me às relações de poder, que a ANT se recusa a mobilizar como ferramenta teórica. Segundo Latour (2012, p. 127), “como 'virtude dormitiva do ópio', ridicularizada por Molière, o 'poder' não só põe os analistas a dormir, o que nem importa tanto assim, como também tenta anestesiar os atores - e isto é um crime político". 0 trabalho descritivo consiste em seguir lentamente os atores e toda a rede de aliados que os sustentam "mantendo tudo liso" (LATOUR, 2012, p. 275), para evitar saltar de plano para explicações transcendentes. Nesse ponto o feminismo diverge da ANT, mas não diverge com um apelo à transcendência. Ao operar com base no dualismo entre moças e rapazes, 0 feminismo não pode deixar de perceber as estratégias rugosas que estão em jogo, porque não descrever as artimanhas das relações de força significa ou inocência ou má intenção. E, em certo sentido, não descrever as relações como relações de força e sempre rugosas - e, portanto, de poder significa exatamente anestesiar a perspectiva feminina e todos os outros que têm suas ações negligenciadas pela história. Desse ponto de vista, a ANT corre 0 risco de fazer sempre determinadas relações de força aparecer de forma um tanto solidárias, na medida em que são matematizadas pela "associação" e, nesse sentido, pensar no casal como uma "ação-rede", ou um "agregado" é uma forma de encobrir desigualdades.

Como mostraram autoras feministas (KELLER, 1985; CORRÊA, 2003 - para ficar somente com algumas), essa relação de poder intrínseca ao trabalho 
científico em parceria de casais é bastante ambígua: por um lado, possibilitou às mulheres trabalharem em territórios geralmente interditos para o feminino; por outro, acabaram por diminuir sua importância no trabalho. Marie Curie nunca foi considerada uma cientista como todos os outros; ela fora posta à margem do agenciamento da radioatividade, produzida como uma exceção que era carregada pelo "casal". Assim, ocupava uma posição do "meio", em relação às características concebidas como inerentes a mulheres no geral (que eram muitas coisas), mas também, como uma mulher capaz de produzir ciência como homem (o que não quer dizer que ela se tornou homem, ou se masculinizou). Esse tratamento parece ser parte da relação de poder que a comunidade científica, em sua maioria masculina (no sentido qualitativo do termo), exercia sobre ela - a única possibilidade de continuar.

Porque se é verdade que a aliança com Pierre Curie por meio do dispositivo experimental da radioatividade possibilitou à cientista ocupar espaços historicamente masculinos, esse habitar se deu sempre de forma excepcional e marcado. Se o casal é uma aliança de um lado, porque arrasta Marie Curie a territórios inauditos, de outro é uma armadilha: o "ponto de vista do casal Curie", "a rede do casal Curie", é sempre uma visão holística e romântica em que 0 feminino é subsumido pelo masculino, que se mantem desmarcado como ponto de vista total. A definição da ANT como uma ontologia plana é abertamente definida pela influência de Deleuze (LATOUR, 2012). No entanto, tanto Deleuze quanto Guattari definiam o plano de consistência de seus rizomas nas complexas relações entre o liso e o estriado. Se a ANT se pretende uma descrição de superfície "tão profunda quanto a pele", não pode deixar de levar em consideração os poros, as rugas, as marcas, as espinhas, as pintas que compõem 0 plano. As redes não são constituídas sem desníveis. Voltemos ao "caso Marie Curie".

Por volta de 1899, devido à necessidade de dar respostas às hipóteses que tinham lançado sobre a radioatividade e os radioelementos, os Curie dividem 0 trabalho. Em primeiro lugar, o casal saiu em busca de recursos para a pesquisa sobre a radioatividade, e Pierre começou a exercer "ofício do chefe", como sugeriu Latour (2000). Era preciso conseguir material bruto para a pesquisa de purificação do polônio e do rádio (toneladas de pechblenda - variedade impura de uraninita) e outros instrumentos laboratoriais para explorar a origem da atividade dos raios emanados. A casa era o território em que as mulheres circulavam por excelência (e, nesse sentido, para 0 casal Curie o laboratório se tornava uma extensão da mesma), e era ali que o enunciado da "complementaridade sexual" circunscrevia as mulheres. Assim, o marido parte para "fora" do laboratório, 
buscando viabilizar a pesquisa de sua esposa; agora também capturada em seu nome. Enquanto isso, Marie Curie continuava o trabalho de purificação de sais cada vez mais puros das substâncias candidatas - porque ainda em via de estabilização - a novos elementos químicos, enquanto dividia essa atividade com os serviços domésticos.

Em segundo lugar, a divisão sexual do trabalho também informa as atividades dentro do laboratório. Marie seguiria com o trabalho de purificação de sais ativos puros, ao passo que Pierre iria em busca de compreender qual a origem da energia radioativa - as analogias que possibilitariam conhecer a causa do fenômeno. Segundo Stengers e Bensaude-Vicent (1996), física e química não tinham suas fronteiras bem definidas no momento, e nesse sentido a radioatividade não representava uma disciplina. A física era o "carro chefe" enquanto a química era uma espécie de "física" de menor monta. A divisão do trabalho sexual no laboratório e a incomensurabilidade política que carregava acompanhavam exatamente essa diferença. Desse modo, Marie dirigiu seus esforços para uma atividade química, e Pierre ficou com a parte da física. Certamente, as vicissitudes de gênero dividiram tais tarefas e foram objetivadas nas figuras de Marie e Pierre Curie.

Historicamente, a física é concebida como uma disciplina mais reflexiva, e sua compreensão depende muito mais da "capacidade mental" daquele que faz a pesquisa. Em relação a esta, a química é um trabalho arquitetado como mais motorizado, depende menos do raciocínio e mais de experimentos laboratoriais práticos (STENGERS \& BENSAUDE-VICENT, 1996). Tudo se passava nesse plano de atualização do poder, como se estivesse o feminino para a química, assim como 0 masculino para a física. Se disse que Marie Curie fora colocada numa posição de menor prestígio no que diz respeito às pesquisas de substâncias radioativas, porque seu trabalho foi deslocado para a parte mais "braçal", que significava a manipulação dos resíduos do pechblenda em caldeirões ferventes, depois a destilação química etc. Pierre, por sua vez, a ajudava enquanto aguardava os sais "cada vez mais ativos" para as medições e reflexões ulteriores. 0 primeiro trabalho era parte constituinte do segundo, mas este estava expresso numa posição intelectualmente mais nobre.

Logo esta divisão sexual começou a criar extensões para além do trabalho laboratorial, mas também nas premiações e nas oportunidades de trabalho. Na última sessão da Academia de Ciências de Paris, no ano de 1901, foram anunciados os diversos prêmios para os grandes senhores da ciência local. Foi quando Pierre descobriu que deveria receber o prêmio La Caze, um dos mais 
interessantes e prestigiados da França no momento. A comissão do prêmio escreveu as memórias: "A comissão concede por unanimidade o prêmio ao senhor Pierre Curie. A descoberta do rádio marcou de modo célebre no mundo inteiro o nome de senhor Pierre Curie, associado a sua eminente colaboradora Madame Curie". ${ }^{5}$ Por outro lado, Pierre receberá um convite para trabalhar na Sorbonne, enquanto Marie Curie recebeu a proposta de ministrar aulas para moças numa pequena (mas tradicional) escola no interior de Paris. Marie Curie só conquistaria uma vaga "especial" na Sorbonne, ocupando "temporariamente" - por tempo indeterminado - a vaga de Pierre, por ser a única na França disponível e capaz de exercer essa atividade vinculada à radioatividade (GOLDSMITH, 2006).

Qualquer cientista (homem, francês) que trabalhou como Marie em pesquisas importantes na França conheceu melhores possibilidades. Assim, o exercício de poder e a divisão de forças distribuíam os papéis de forma que a cientista sempre aparecesse como uma mera auxiliar do marido. Essa maneira de atualização do poder, suas diversas formas criativas de capturas, mantinha Marie Curie numa posição de anômala no círculo de cientistas e assim fazia dela, sempre, uma habitante da borda, no entanto, sempre presente.

Pode-se observar que a palavra anômalo, adjetivo que caiu em desuso, tinha uma origem bem diferente de anormal: a-normal, adjetivo latino sem substantivo, qualifica o que não tem regra ou 0 que contradiz a regra, ao passo que 0 adjetivo a-nomalia, substantivo grego que perdeu seu adjetivo, designa 0 desigual, o rugoso, a aspereza, a ponta de desterritorialização. (DELEUZE \& GUATTARI, 1997, p. 25).

\section{ENTRE EXTENSÕES E INTENSÕES}

Mas ainda resta uma segunda questão para a ANT. Segundo Latour (2000), um cientista se faz vencedor quando consegue mobilizar um número maior de agentes em torno do seu experimento para estabilizá-lo; um fato resiste às falsificações de acordo com a extensão dos elementos heterogêneos que ele agregou, de forma que os fatos, assim, tornam-se indiscutíveis. 0 laboratório é a

\footnotetext{
5 Ver comptus rendus, 1901. Disponível em Institut de France - Académie des Sciences (www.academie-sciences. $f r$ ). Essa mesma conduta pode ser observada no Nobel de física de 1903, que premiou as pesquisas sobre a radioatividade, como descrito em outras oportunidades (PUGLIESE, 2012a; 2012b; 2009). Os prêmios eram atribuídos ou a Pierre Curie ou ao "casal", tal como se Marie fosse uma extensão do marido.
} 
fonte de poder de fazer-falar os fenômenos da natureza, é o dispositivo que torna possível o cientista testemunhar não somente a existência de um determinado fenômeno, mas também os feitos das entidades em questão (LATOUR, 1994; STENGERS, 2002). Com o avanço das pesquisas, e sem os recursos necessários, os Curie sabiam que não conseguiriam fazer frente aos novos experimentos, quer dizer, aos "contra-laboratórios" (LATOUR, 2000) que colocavam em xeque algumas das hipóteses que haviam levantado. Ou seja, tornar-se-ia quase impossível fazer a radioatividade testemunhar de uma forma diferente da que laboratórios de grande poder agenciavam.

Descrevo essas derrotas mais detalhadamente em outras oportunidades (PUGLIESE, 2012a; 2012b). Somente para exemplificar, considerando os fins do presente artigo, podemos destacar uma controvérsia que se aflorou após a premiação do Nobel de 1903: as teses de Pierre Curie sobre a atividade externa da radioatividade que 0 átomo absorveria e depois dispensaria em forma de radiação foram falsificadas pela teoria da transmutação atômica de Ernest Ruterford e Frederick Soddy, em seu grande laboratório no Canadá. Sem os mesmos equipamentos os Curie não puderam defender mais seu ponto de vista na controvérsia.

De todos os cientistas que participavam das controvérsias seguintes em torno da radioatividade, os Curie eram os únicos que não possuíam um espaço considerado adequado. Marie Curie enfatizou, anos depois, referindo-se sem dúvida à estrutura mobilizada pelos outros pesquisadores: "estava em extrema desvantagem, por conta das condições inadequadas, pela falta de local apropriado onde trabalhar, pela falta de dinheiro e de pessoal" (CURIE, 1963, p. 82). As pesquisas sobre a radioatividade, para 0 bem ou para 0 mal, estavam sondando 0 interior do átomo, e isso, sem dúvida conduziria à necessidade de mais equipamentos que pudessem dar conta do problema. Quando "os Curie" receberam Rutherford em seu estabelecimento laboratorial para dar-lhe a amostra de rádio extraída por Marie Curie, o maior de seus concorrentes disse: "deve ser horrível não ter um laboratório". E o químico Wilhelm Ostwald observou num outro momento: "insisti em ver o laboratório. Parecia um estábulo ou um depósito de batatas e, se não tivesse visto a mesa de trabalho com equipamentos de química, acharia que estavam mentindo" (apud GOLDSMITH, 2006, p. 78).

A estabilização da radioatividade não me parece estar ligada somente à "extensão" de sua rede, mas muito mais à "intensão" de seu dispositivo experimental. 0 que não quer dizer que a extensão das associações feitas "em nome da radioatividade" não tenha importância, ou mesmo que não componha 0 
que faz da radioatividade um "fato duro", muito pelo contrário. A extensão da rede me parece muito mais um dos efeitos do dispositivo experimental de Marie Curie do que a própria explicação de sua efetividade. Se os fatos se tornam duros por conta da extensão das redes criadas pelos cientistas, como explicar o sucesso de cientistas minoritários sem recursos e com um "galpão de batatas"? Em minha opinião, essa dificuldade tem a ver, mais uma vez, com a maneira pela qual 0 poder funciona na obra de Latour: tal como um espectro auto-evidente que opera sempre como "produto da rede", de "sua extensão", o poder é transformado em uma instância quase quantitativa (redes maiores ou menores), e isso o torna muito homogêneo e retilíneo. Para não dizer autoexplicativo demais ${ }^{6}$.

Ora, mas o poder (com "p" minúsculo) é menos algo contrário às redes, no sentido de não atribuir valor a elas, do que aquilo que faz com que as redes sejam constituídas de uma ou outra maneira. "O poder não está para além da rede numa verdade que nos pouparia de ter que acompanhar a construção de ramificações e permitiria deduzi-la. Mas ele qualifica a rede e estabelece seus limites, ou seja, os pontos em que a noção de interesse muda de sentido, onde cessamos de nos dirigir aos protagonistas que se trata de conseguir interessar e onde começam as estratégias que pressupõem que 0 interesse possa ser comandado". (STENGERS, 2002, p. 153). Afinal, exatamente por terem construído redes menores os Curie foram vencidos em boa parte das controvérsias acerca da origem da energia. Mesmo assim, até os dias de hoje, a radioatividade é um fenômeno ligado ao casal e, principalmente a Marie Curie - exatamente por conta de outras relações de poder ulteriores vinculadas à "purificação do rádio". Pois, considerando a divisão sexual do trabalho dos Curie - isto é, entre física e química, entre teoria e prática, - essa derrota sobre a natureza da matéria tem uma implicação importante nas relações de gênero. Afinal, como disse Jean Perrin - um dos descobridores dos elétrons - anos depois: "a purificação do rádio é a pedra angular de todo o edifício da radioatividade". Esse tinha sido o trabalho químico de Marie Curie outorgado pela divisão sexual das atividades no laboratório dos Curie.

É que entre (e antes) da extensividade das associações há inúmeras intensidades: dobras, desníveis, os qualificativos das relações de força que tornam

\footnotetext{
${ }^{6}$ Nesse sentido, poderia me esforçar para, artificialmente e a posteriori, fazer 0 "casal Curie" ter construído uma rede maior que seus concorrentes para dar conta de seu sucesso. E se as redes são um recurso do analista, a explicação por meio da extensão não está do seu lado? "0 poder de tais redes analíticas é também o seu problema: teoricamente, elas são ilimitadas. Se elementos diversos fazem uma descrição, eles podem ser vistos como extensíveis ou retraídos na medida em que a análise é extensível ou retraída" (STRATHERN, 1996, p. 523).
} 
sempre latentes os mecanismos de poder, a sua multiplicidade. "Uma multiplicidade se define, não pelos elementos que a compõem em extensão, nem pelas características que a compõem em compreensão, mas pelas linhas e dimensões que ela comporta em intensão" (DELEUZE \& GUATTARI, 1996, p. 2427). Essas dimensões certamente implicam no modo como as associações são constituídas - elas dependem crucialmente da posição de cada elemento da rede, da força que limita em "intensão" alguns e potencializa outros ao estabelecer relações "em nome dos fatos científicos".

\section{COISAS DE GÊNERO E O GÊNERO DAS COISAS}

0 "Caso Marie Curie" pode se tornar uma ótima "equação" para experimentar e discutir as dificuldades por parte das análises feministas em abordar as Hard Sciences, expressas na introdução do livro de Keller e Longino (1996). Afinal, Marie Curie é uma representante feminina na história das Hard Sciences, a reconhecidamente mais visível e mais importante de todas elas, em um lugar historicamente menos propício. Talvez, pela primeira vez, a "exclusão" do feminino na prática científica moderna não foi auto evidente, e por isso mesmo 0 gênero da ciência tão bem problematizado. Sabe-se, até hoje, das dificuldades de mulheres trabalharem em territórios como a física ou a química (KELLER \& LONGINO, 1996). As autoras vêm mostrando há algum tempo como uma "ideologia debilitante" promove distorções nas ciências da vida, nas quais as pesquisas envolvem claramente categorizações de sexo/gênero: a célula, o órgão, 0 gene, o gameta etc. Mas por outro lado, argumentam as autoras que o número pequeno de pesquisas nas ciências exatas, associado à ausência de categorização sexo/gênero nos objetos de pesquisa dificulta os estudos feministas nessas áreas, onde o número de mulheres é ainda menor.

Keller (1983), por exemplo, desenvolveu uma oposição bastante conhecida na literatura feminista entre a "objetividade estática" e a "objetividade dinâmica". A primeira, produto da ciência feita por homens, é o controle da natureza; e, a segunda, produto da ciência feita por mulheres, é a integração com a natureza. Com ênfase numa teoria psicanalítica das relações objetais, a autora afirma que a "objetividade dinâmica" é fruto de um híbrido entre amor, força e conhecimento, ou seja, uma relação mais emocional entre sujeito e objeto. Isso, segundo ela, é fruto da socialização diferente entre homens e mulheres no período da infância, quando homens aprendem a dominar e mulheres a integrar. Em sua tese sobre MacClintock, uma bióloga vencedora do prêmio Nobel, Keller evidencia tal objetividade a partir de uma expressão da própria cientista: "sentir o organismo". 
A "objetividade dinâmica", como uma perspectiva, seria nada mais do que uma forma de positivar os traços femininos na construção do conhecimento, a ponto de enaltecer a contribuição das mulheres às pesquisas científicas. Mas em meu ponto de vista, o problema das relações entre gênero e ciência não está nesse lastro irredutível de perspectivas dotadas de gênero. Porque esse tipo de argumento, geralmente, repõe alguns espectros essencialistas que se pretende combater.

Se a análise da ciência - e, em particular, do modo como o gênero se constitui enquanto operador importante - for marcado pelo antropocentrismo que se materializa na figura dos cientistas, teríamos de encontrar em sua posição marcada uma "intencionalidade anterior", que faz de sua ciência uma perspectiva dotada de gênero - já que 0 androcentrismo, como posição fora do mundo, ressoa sempre a partir da posição dos rapazes. Penso que esse sempre foi um dos combates do pensamento feminista ${ }^{7}$. Por outro lado, estudar as relações entre humanos e coisas somente levando em consideração apenas as ações humanas só permite compreender metade do problema. Considero que uma das dificuldades da perspectiva feminista com as hard sciences está vinculada a esse impasse. Ele acontece, em minha opinião, por conta do cognitivismo exagerado que impõe um dualismo irredutível e essencial entre homens e mulheres na prática científica, como se os fenômenos estudados no laboratório fossem somente reflexos das formas como as relações de gênero atuam por meio do trabalho dos cientistas, sem qualquer recalcitrância. Nesse ponto a ANT pode colocar algumas boas questões para os estudos feministas da ciência.

Marcadas pela dualidade masculino/feminina, as relações entre humanos e não humanos geralmente não passam para um terceiro elemento, como disse Donna Haraway (1991) - que insiste no fato de que o feminismo tem que aprender a contar no mínimo até três. Uma forma de fazer isso é atribuir um substrato "ativo" às coisas que não são dotadas de gênero (como, por exemplo, a radioatividade, as equações matemáticas, ou os quarks ou os léptons). No entanto, apesar da lucidez da questão, a própria autora reencontra 0 problema, pois a maioria de seus exemplos de "atividade de objetos" são sexuados, muito embora porque geralmente vinculados às ciências biológicas que ela problematiza e nas quais essa categorização é constituinte dos seres (HARAWAY, 1995) ${ }^{8}$. 0 trabalho de

\footnotetext{
${ }^{7}$ Como lembrou Donna Haraway, "não existe nada no fato de ser 'mulher' que naturalmente una as mulheres. Não existe nem mesmo uma tal situação - 'ser' mulher" (HARAWAY, 2000, p. 52).

${ }^{8}$ Atualmente existem várias iniciativas teóricas de superar o binarismo de gênero, multiplicando-o com os cortes de raça, sexualidade etc. A ideia aqui é contribuir com outros elementos com essa
} 
Marie Curie, foi exatamente "purificar" os elementos constitutivos das relações de gênero e as técnicas disponíveis para produzir ciência. Essa purificação, no entanto, longe de produzir uma separação radical entre gênero e ciência que constituiria um abraço do "falogocentrismo", reembaralha as cartas conceituais e subverte 0 gênero na mesma medida em que aponta para uma singularidade da ciência. A relação política de Marie Curie com a radioatividade não é nem racional nem espontânea, ela se dá por meio do devir.

Se Marie Curie tivesse ou se apegasse a um modo feminino especial de fazer ciência, o dispositivo experimental da radioatividade não poderia se tornar a pedra angular da subversão do gênero (PUGLIESE, 2012a). Carregando a atividade laboratorial de gênero, como se o seu ponto de vista feminino fizesse-ver algo não evidente para os concorrentes, não teria espaço para o dispositivo experimental da radioatividade e, assim, o fenômeno não poderia ser caracterizado pela suas próprias ações. Não à toa, uma forma de colocar em questão a existência da radioatividade era dizer que essa era uma "coisa de mulher" (como fez Poincaré, em 1898) - tanto no sentido da ação de Marie Curie, quanto no resultado dessa ação: a radioatividade era somente uma representação, e uma má representação da natureza do fenômeno. Ora, é isso exatamente o que o dispositivo experimental permitiu afastar.

Marie Curie provavelmente se reconhecia como "autora" da radioatividade, mas isso pouco importa. A relação de força que seu dispositivo experimental criou impossibilitava que seus colegas cientistas pudessem usar desse argumento contra ela, acusando-a de "ter falado em nome da radioatividade" ao invés de ter "feito a radioatividade falar" (PUGLIESE, 2009). É nesse sentido que o dispositivo experimental põe em xeque a noção de "representação" - enquanto uma relação cognitiva de um sujeito, na qual se cria uma perspectiva dotada de gênero sobre 0 objeto. Afinal, a singularidade política do dispositivo experimental consiste em fazer da própria radioatividade uma perspectiva (PUGLIESE, 2012a; STENGERS, 2002). Esse dispositivo implica em uma caracterização do fenômeno de um tal modo que todo aquele que quisesse experimentá-lo no laboratório, mesmo para

multiplicação. "Se considerarmos os grandes conjuntos binários [molares], como os sexos e as classes, vemos que eles correm também nos agenciamentos moleculares de outra natureza e que há uma dupla dependência recíproca, pois os dois sexos remetem a múltiplas combinações moleculares, que põem em jogo não só o homem na mulher e a mulher no homem, mas a relação de cada uma com o outro, com o animal, planta etc.: mil pequenos sexos" (DELEUZE \& GUATTARI, 1996, p. 90-91). Não só as relações com plantas, animais, podem multiplicar o sexo, ora, talvez o "etc.", também possa estar associado aos fenômenos assexuados da física e da química. 
contestá-lo, teria que seguir os mesmos passos de Marie Curie. Essa forma de salvar o fenômeno cria uma força capaz de calar os outros "autores" que desejem experimentá-lo de outro modo que não esse. Uma vez salvo, o fenômeno da radioatividade fazia proliferar Marie Curie, subvertendo as relações de gênero na medida em que todo experimentador é capturado pelo devir-mulher que ele suscitou?'

\section{A RADIOATIVIDADE FRENTE À PERSPECTIVA FEMINISTA}

Um outro problema esbarra na tentativa de estender as categorias de gênero, isto é, o par masculino/feminino para os objetos que não assumem categorizações de gênero (a radioatividade é um fenômeno masculino ou feminino?) negando-lhes um estatuto ontológico que escape desse binarismo. Todo o trabalho de Marie Curie como "autora" da radioatividade consistiu em um faz-fazer, isto é, trabalhar para que a radioatividade agisse independente de sua ação - que era dotada de gênero. Aí está o gênero da ciência: o dispositivo experimental da radioatividade pode ser repetido por todo aquele que quiser experimentar o fenômeno, independentemente de sua qualidade de sujeito. Ora, é exatamente pelo modo como a radioatividade e o seu dispositivo experimental carregam em seu seio um gênero "neutro" que sua política pode promover uma variação do estatuto significante masculino/feminina. Marie Curie conseguiu estabelecer a radioatividade como um fenômeno natural, na medida em que seu dispositivo experimental "dessexualizou" a radioatividade, não o contrário. Afinal, por conta de seu dispositivo experimental, estava a radioatividade (e, portanto, Marie Curie) para o racional, assim como as desigualdades de gênero para 0 subjetivo, para o não científico, para o obscuro e o irracional. Marie Curie devém em parte do dispositivo experimental da radioatividade, ao mesmo tempo em que a radioatividade devém da política que joga Marie Curie para um espaço indevido, inaudito pela imagística sexual.

0 que a ANT tem a oferecer aos estudos feministas é que levar em consideração (simétrica) a ação dos não humanos pode ser a chave para compreender um conjunto de relações, incluindo as relações de gênero. Ora, a

\footnotetext{
${ }^{9}$ Descrever 0 acontecimento de tal modo permite escapar de uma certa chantagem da história das ciências. Isto é, das histórias de veneração da objetividade nua e crua, amiga de uma natureza transcendente, e das histórias de denúncia da ciência como contos de fada que insistem em destituir sua singularidade. Seguindo a argumentação de Stengers (2002), a ideia é desenvolver a singularidade da ciência sem corroborar uma estética trágica de uma ciência redutora e reduzida, nivelada em ambos os lados: a nivelar e endurecer as diferenças.
} 
política resultante do dispositivo experimental da radioatividade é da ordem do devir: criou "núpcias" entre Marie Curie e a radioatividade - devir-radioatividade de Marie Curie, e devir-mulher da radioatividade, que são produzidos em um corte transversal que arrasta uma e outra para espaços indevidos, fazendo-as variar com os outros elementos que capturam. "Evolução a-paralela de dois seres que não têm nada a ver um com outro" (DELEUZE \& PARNET, 2004). Chamei os efeitos desse dispositivo experimental nas relações de gênero de radiopolítica (PUGLIESE, 2012a). Afinal, quanto mais Marie Curie, através de seu dispositivo experimental, trabalhava para fazer da radioatividade e dos radio-elementos uma perspectiva, isto é, uma ontologia menos vacilante, mais a radioatividade a tornava visível enquanto cientista, fazendo-a ocupar territórios improváveis para as mulheres. A força política que a radioatividade continha fazia as formas significantes da política sexual "gaguejarem", abrindo espaço para variações e fissuras nas relações de gênero. A radiopolítica é exatamente esse meio de intensidade (de poder criador de devir) que envolve a núpcia contra-natureza do "sexo" e da "ciência": o primeiro porque transforma os papéis e os atributos significantes pré-estabelecidos às mulheres abrindo uma possibilidade de trabalho para Marie Curie; a segunda, porque a radioatividade enquanto uma propriedade atômica implica numa possibilidade nova para a ciência.

Essa "evolução a-paralela" entre Marie Curie e a radioatividade, tomava os cientistas - os homens inclusive - transformando toda e qualquer afirmação negativa em relação à radioatividade em obscurantista e irracional. Digo isso porque o realismo produzido pelo dispositivo experimental de Madame Curie abria a possibilidade para uma política que (des)caracterizava a desigualdade de gênero numa espécie de fetiche sexista, ou seja, numa ideologia discriminatória indigna da ciência. A sua singularidade não cessou de iluminar as estratégias de poder e trazê-los à tona, criando um problema para certos mecanismos vigentes. 0 que não quer dizer que pararam de funcionar. 0 fenômeno da natureza, a radioatividade, operava como um centro de ressonância que obliterava as relações de poder. A cada nova estabilização da radioatividade, já carregada pelo devirmulher em que se constituiu, eram criadas fissuras nas relações convencionais de gênero, na medida em que Marie Curie era arrastada junto com o fenômeno da natureza. Se o poder se transformava abrindo espaços para Marie Curie como fruto da radiopolítica, não se deve supor que ela estivesse numa posição exterior à distribuição binária do poder que o gênero conformava, isto é, fora da partilha que constituía homens e mulheres.

Ora, toda vez que alguém encena a radioatividade em um laboratório, torna-se um pouco Marie Curie por meio de seu dispositivo experimental, pois 
tem de seguir exatamente os seus passos para tornar o fenômeno visível. As redes vinculadas à radioatividade e todo 0 seu pessoal são extensões desse acontecimento. 0 dispositivo experimental é exatamente a forma de conferir um poder de existência própria a fenômeno: uma forma de expressão que confere à radioatividade o poder de atribuir a Marie Curie o direito de falar em seu nome ${ }^{10}$. A partir de seus procedimentos laboratoriais, seguiu uma discussão da ordem do "como" se dava a atividade dos raios: como se comportavam em relação às purificações químicas exigidas, mas também em relação ao trato com os instrumentos laboratoriais, fazendo com que o seu "porquê" funcionasse da forma "como" ela havia identificado.

É "em nome da radioatividade" que Marie Curie dividia os espaços com os "homens de ciência" e, principalmente, é com base nas questões que a radioatividade colocava que ela se tornou uma exceção - a despeito do fato de concordarem ou discordarem dela. Ora, foi "em nome da ciência da radioatividade" que homens e mulheres acabaram levados pelo devir-mulher (que não pode ser confundido com as mulheres e nem mesmo com Marie Curie) que a radiopolítica carregava, autorizando Marie Curie, essa anômala que ganhava mais e mais força, a figurar entre eles. Fazendo-se existir a radioatividade (que passou a ser progressivamente majoritária entre os cientistas), possibilitou-se uma fissura, uma linha de fuga para a produção científica de Marie Curie. "As mulheres, seja qual for seu número, são uma minoria (...) elas só criam tornando possível um devir, do qual não detêm a propriedade, no qual elas próprias têm de entrar, um devir-mulher que diz respeito ao homem por inteiro, homens e mulheres inclusive" (DELEUZE \& GUATTARI, 1995, p. 134).

No "Caso Marie Curie", a radioatividade é a "fênix que falará todas as línguas de um mundo virado de cabeça para baixo" sobre a qual escreveu Donna Haraway $^{11}$. E não Madame Curie, o "sujeito dominado". A radiopolítica subverte internamente 0 gênero, pois arranca Madame Curie de qualquer identidade substancial criada pelo poder (e o transforma "desindividualizando"), fazendo a cientista "vir-a-ser" sempre outra coisa que não "uma mulher", como sujeito marcado. E, "não se trata aqui de androginia nem de um hipotético terceiro gênero, ao invés disso, de uma subversão interna, em que o binário é tanto pressuposto como multiplicado, a ponto de não fazer mais sentido" (BUTLER,

\footnotetext{
${ }^{10}$ Ver Stengers (2000).

11 "O falogocentrismo foi ovulado pelo sujeito dominador, o galo inseminador das galinhas permanentes da história. Mas no ninho com este ovo prosaico foi posto o germe de uma fênix que falará todas as línguas de um mundo virado de ponta cabeça" (HARAWAY, 2004, p. 246).
} 
2008, p. 183). Quanto mais a radioatividade estabilizava-se ontologicamente, mais o poder local do gênero variava, e mais Marie Curie tornava-se a exceção. A cientista fugia à complementaridade sexual, não mais correspondendo a uma simples auxiliadora do marido. Marie Curie era cientista, doutora, descobridora da radioatividade e do rádio, o elemento-santo, duas vezes vencedora do prêmio Nobel etc. Uma exceção. 0 que fez com que dispositivos de poder se atualizassem em outro plano (como o de nacionalidade), não deixando de compor a vida da cientista, exercendo-se em outras linhas. Ao se interditar Marie Curie em alguns territórios através da política sexual ou nacionalista convencional, não se conseguiu parar 0 devir-mulher que a radioatividade encenava. Se o rádio, 0 polônio, enfim, a radioatividade se proliferavam infinitamente, Marie Curie não deixava de "ir junto", como um vírus, independentemente da regularidade do discurso materializado em algumas instituições e que apareciam como resistentes a seu sexo ou sua origem.

\section{NOTA FINAL}

A radioatividade é uma exceção, Marie Curie também o é. A radioatividade tornou-se um fato duro, por conta do incansável trabalho de Marie Curie na construção de um dispositivo experimental durável e, depois, por toda a rede de aliados humanos e não humanos que ela constituiu em nome do fenômeno que "salvou" em seu laboratório. Marie Curie tornou-se uma exceção, uma legenda da história da ciência universal, graças à estabilização da radioatividade enquanto um fenômeno natural e todo o conjunto de fatos científicos e novos elementos químicos que dela se desdobraram. 0 devir-radioatividade de Marie Curie é alimentado por um devir-mulher da radioatividade.

Por isso trata-se de um "caso ilustrativo" - como se diz em matemática (STENGERS, 2002), ele não me serve para provar nada, nenhuma teoria ou atavismo político, mas permite explorar as maneiras pelas quais descrevemos as situações e suas consequências. Espero ter feito a minha caracterização do "Caso Marie Curie" e os problemas que ele produz reagirem - no sentido químico do verbo - com as formas descritivas da Teoria Ator-Rede e da perspectiva feminista, "desobviando" alguns de seus pressupostos. 


\section{REFERÊNCIAS:}

BUTLER, Judith. Problemas com gênero. Feminismo e subversão da identidade. Rio de Janeiro: Civilização Brasileira, 2008.

CORRÊA, Mariza. Antropólogas e Antropologia. Belo Horizonte: Ed. UFMG, 2003. CURIE, Marie. Pierre Curie. With the autobiographical notes of Marie Curie. Nova York: Dover, 1963.

DELEUZE, Gilles; GUATTARI, Felix. Mil Platôs: capitalismo e esquizofrenia, v. 1. São Paulo: Ed. 34, 1995.

DELEUZE, Gilles; GUATTARI, Felix. Mil Platôs: capitalismo e esquizofrenia, v. 3. São Paulo: Ed. 34, 1996.

DELEUZE, Gilles; GUATTARI, Felix. Mil Platôs: capitalismo e esquizofrenia, v. 4. São Paulo: Ed. 34, 1997.

DELEUZE, Gilles; PARNET, Claire. Diálogos. Lisboa: Relógio D’Água, 2004. GOLDSMITH, Bárbara. Gênio obsessivo: o mundo interior de Marie Curie. São Paulo: Companhia das Letras, 2006.

HARAWAY, Donna. Simians, Cyborgs, and Women: The Reinvention of Nature. Nova York: Routledge, 1991.

HARAWAY, Donna. Saberes localizados: a questão da ciência para o feminismo e 0 privilégio da perspectiva parcial. Cadernos Pagu, Campinas, n. 5, 1995.

HARAWAY, Donna. Manifesto ciborgue: ciência, tecnologia e feminismo-socialista no final do século XX. In: SILVA, Tomaz Tadeu da (Org.). Antropologia do ciborgue: as vertigens do pós-bumano. Belo Horizonte: Autêntica, 2000, p. 37-130.

HARAWAY, Donna. "Gênero" para um dicionário marxista. Cadernos Pagu, Campinas, n. 22, p. 201-246, 2004.

HARDING, Sandra. The Science Question in Feminism. Londres: Cornell University Press, 1986.

KELLER, Evelyn Fox. Felling for the Organism: The Life and Work of Barbara MacClintock. Nova York: W. H. Freeman, 1983.

KELLER, Evelyn Fox. Reflections on gender and science. New Heaven: Yale University Press, 1985.

KELLER, Evelyn Fox; LONGINO, Helen (Org.). Feminism and Science. Oxford University Press, 1996. 
LATOUR, Bruno. Jamais fomos modernos. São Paulo: Ed. 34, 1994.

LATOUR, Bruno. Ciência em ação. São Paulo: Ed. Unesp, 2000.

LATOUR, Bruno. A esperança de Pandora: ensaios sobre a realidade dos estudos científicos, Bauru: Edusc, 2001.

LATOUR, Bruno. Reflexão sobre o culto moderno dos deuses fe(i)tiches. Bauru: Edusc, 2002.

LATOUR, Bruno. Reagregando o social: uma introdução à Teoria Ator-Rede. Salvador-Bauru: Edufba-Edusc, 2012.

PUGLIESE, Gabriel. Um Sobrevôo no Caso Marie Curie. Um experimento de antropologia gênero e ciência. Revista de Antropologia, v. 50, p. 347-385, 2009. PUGLIESE, Gabriel. Sobre o Caso Marie Curie. A radioatividade e a subversão do gênero. 1. ed. São Paulo: Alameda/Fapesp, 2012a.

PUGLIESE, Gabriel. Entre o divisível e o indivisível. o Caso Marie Curie, a composição da matéria e a política sexual. Teoria \& Sociedade (UFMG), v. 18, p. 92-115, 2012b.

STENGERS, Isabelle. "Para além da grande separação, tornamo-nos civilizados?". In: SANTOS, Boaventura Sousa (Org.). Conbecimento prudente para uma vida decente. Lisboa: Cortez, 2006.

STENGERS, Isabelle. Entre Deleuze e Whitehead. In: ALIEZ, Eric (Org.). Gilles Deuleuze: uma vida filosófica. São Paulo: Ed. 34, 2000.

STENGERS, Isabelle. A invenção das ciências modernas. São Paulo: Ed. 34, 2002.

STENGERS, Isabelle; BENSAUDE-VINCENT, Bernadette. História da química. Portugal: Instituto Piaget, 1996.

STRATHERN, Marilyn. Cutting the Network. The Journal of the Royal Anthropological Institute, v. 2, n. 3, 1996.

STRATHERN, Marilyn. No limite de uma certa linguagem (entrevista com a autora). Mana, UFRJ, v. 5, n. 2, 1999.

STRATHERN, Marilyn. O Gênero da dádiva. Campinas: Ed. Unicamp, 2006.

WHITEHEAD, Alfred North. O conceito de natureza. São Paulo: Martins Fontes, 1994. 